\title{
Smart Power Generation \& Storage TEDOM
}

\author{
Tomáš Bičák ${ }^{1)}$ and Helena Kolomazníková ${ }^{2)}$ \\ 1) 2) TEDOM a.s., Czech Republic, \\ e-mail: ${ }^{1)}$ tomas.bicak@tedom.com, ${ }^{2)}$ helena.kolomaznikova@tedom.com
}

\begin{abstract}
The contribution describes the project implemented in the production plant of TEDOM. It defines the part of the premises where the buildings are supplied with electric power from the photovoltaic power plant in collaboration with a CHP unit. A battery system is employed to compensate for the imbalances between the power generation and consumption. Yet the buildings are completely independent of the connection to the distribution network. Thus, it is a so-called "off-grid" operation.
\end{abstract}

Keywords - off-grid operation, CHP unit, photovoltaic power plant, battery.

\section{INTRODUCTION}

There is a clear trend - a growth in utilisation of the renewable sources of energy. However, with the conditions in the Czech Republic, the generation of energy in the sources dependent on the climatic conditions is highly unbalanced and, in the opinion of the operators of distribution systems, if these sources are used to cover the internal consumption of buildings, it results in reduction of the amount of distributed power while maintaining the requirements for output. This is the reason why the proposal of a new tariff system was introduced in the Czech Republic, which would transfer a significant part of the distribution payments in the low voltage systems to the reserved power input (circuit breaker ratings) at the supply points. This system was not introduced, but the question of conveniently set payments for the distribution services still exists.

The decentralized energy sources can positively contribute not only to reduce the losses in the distribution systems, but also to reduce the demands for the transmitted output. They are also capable of enabling an operation that is completely independent of the connection to the distribution system. The off-grid operation mode is advantageous mainly where the available power input from the distribution system is insufficient or where the connection is troublesome. This makes sense mainly in certain foreign applications.

Big hopes are laid into the photovoltaic (PV) sources in combination with energy accumulation systems. However, if the accumulation of power is to ensure equalization of the send out chart under all circumstances and exclusively in combination with the operation of the PV source, the installed accumulation capacity (and the source output) in the present conditions would be disproportionately high and expensive. This can be imagined rather in the buildings with a low consumption of energy today. The way to efficiently ensure a high utilisation of energy from the renewable source as, for example, PV power plants, and simultaneously reduce the yearly peak consumptions of power from the distribution system is a combination of a number of various technologies. What seems to be a logical accessory in this combination is a technology of combined heat and power (CHP) generation, as is the case with a CHP unit. As the source of energy in small-sized decentralized energy sources, the CHP units predominantly use the gaseous fuel which needs not be only natural gas. For example, biogas, landfill gas or other energy gases, if available can be utilised.

Today, the CHP units with the combustion engine technology are utilised for decentralised energy sources in the power range from $\mathrm{kW}$ up to $\mathrm{MW}$. When power is being produced in a CHP unit, heat is generated. This heat can be employed predominantly to heat or prepare hot water.

In the combined source of power, the primary production of electric energy takes place via the renewable source. The power accumulation evens out the differences in the chart of production from the renewable source and the power consumption chart on daily basis. The long-term deficiency in the production of power in a renewable source can be compensated by the actual production from the CHP unit. It can be simultaneously expected in the winter season that the heat from CHP unit will find its use. In other words, the CHP unit operation will be efficient mainly in the period when the production from the PV source is low. Suitable dimensioning of the sources and accumulation of power and heat can bring an optimum solution which assures high applicability of the renewable source without energy overflowing into the distribution system, effective utilisation of the primary energy from gaseous fuel and minimization of the consumption demands from the distribution system.

The project implemented by TEDOM in one of their production plants can be used as an example. Importance of a correct setting of the electric output of individual sources as well as a planning of links to the supplies of heat and cold can be documented in this project. This example simultaneously documents the options in utilisation of various technologies.

\section{INITIAL CONDITIONS}

The premises of TEDOM in Výčapy include several individual buildings which were gradually reconstructed over the course of previous years. Under conditions before the project implementation, the power supplies were provided by power from the distribution system. At the same time, the CHP units with a total power output of $74 \mathrm{~kW}$ and $152 \mathrm{~kW}$ in heat were installed on the production plant premises. The CHP units supply power into the production plant premises and surplus power into the distribution system, both under the conditions agreed upon with the electric power dealer. A backup energy source of $80 \mathrm{~kW}$ power is installed on the premises ready 
to operate if the power supplies from the distribution system are interrupted. This occurs several times a year.

The annual purchased amount of power for the premises amounts to about $80 \mathrm{MWh}$, with a total annual power consumption of about $180 \mathrm{MWh}$.

The heat from the CHP units is utilized to heat the premises and to prepare hot water. Gas boilers are installed as an additional source of heat. The heating system includes an accumulation tank with a volume of $10 \mathrm{~m}^{3}$ which equalizes the imbalance between production and heat demand during a day.

The buildings are air-conditioned. In the summertime, the production of cold is assured using both a dry absorption cooler with a rated output of $100 \mathrm{~kW}$ and a compressor unit with an output of about $30 \mathrm{~kW}$. The dry absorption cooler makes use of the heat from the CHP units to produce cold energy. The result is the extraction of heat ensured in the summertime as well.

Such part of the premises, which is composed of three interconnected structures "A-B-C" was chosen for the project implementation. In terms of supplies with power, the buildings were placed in the off-grid operation mode that is independent of the distribution network. The buildings continue to be supplied with heat from the central boiler room. Figure 1 gives a schematic representation of the supply of power, heat and cold to separate parts of the premises.

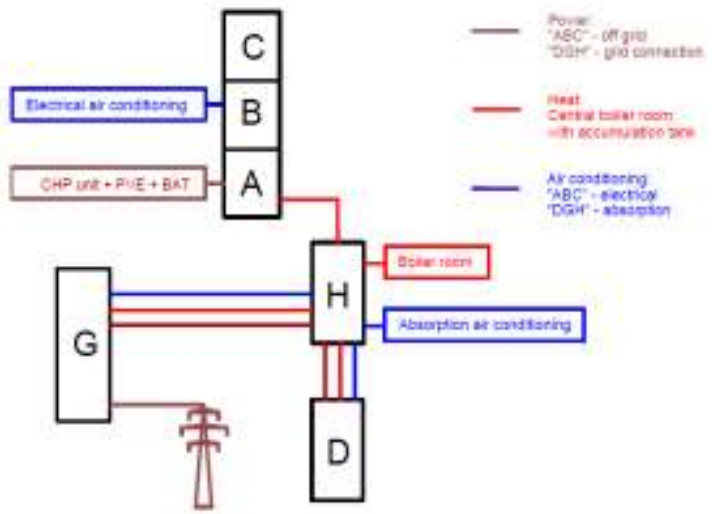

Fig. 1. Supply of energies, Výčapy premises.

The design and production of power switchboards for the CHP units, the service centre with the parts warehouse and assembly workshop, IT Department, Economy Department, and Design Department are all located in the "A-B-C" buildings. Heavy electrical loads such as cranes, lathes, drilling machines and milling machines are also installed in the assembly and service workshops. Appliances with maximum power demand include a material lift and a dry compressor unit. The lift is used for a short period of time with a significant increase in the starting current by as much as $30 \mathrm{~A}$ on one phase. The dry compressor unit has a cyclical consumption of power dependent on operation of individual compressors with a power input of $10 \mathrm{~kW}$ per compressor.

The normal operation in the buildings is unidirectional. This is in conformity with the daily power consumption process when the consumption grows sharply around 6 o'clock a.m. to drop down gradually after 2 o'clock p.m. (Fig. 2). The total power consumption in the specified part of premises is about $68 \mathrm{MWh}$ a year.

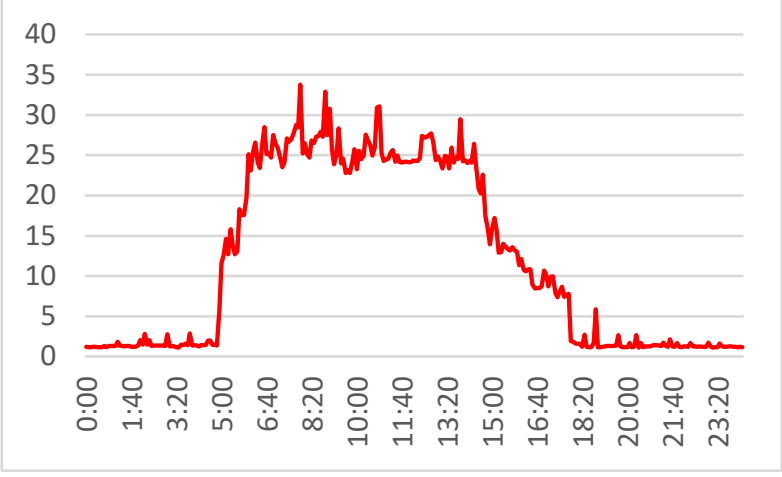

Fig. 2. Consumption process in the "A-B-C" buildings (kW).

\section{Proposed ARRANGEMENT OF SPGS}

The "Smart Power Generation \& Storage" project enables efficient utilisation of energy:

- from renewable source - photovoltaic power plants,

- from highly effective source of energy - CHP units, which are fuelled by natural gas.

The source part was designed so as to prevent any imbalances between the power generation and consumption and useless wasting of the produced energy. Dimensioning of the technological parts is based on detailed information on the power consumptions during a day, as well as in separate days in the year. The correct output of the sources, power accumulation amount, and peak output of individual technologies can be designed exclusively upon detailed information.

The power surpluses, if any, are always utilised in the DC heating of water ("electrical boiler") where the produced heat is conducted to the central boiler room to be further utilised for heating or air conditioning of the premises. This allows for an efficient operation of cogeneration during the summer and winter seasons.

The diagram of the principle of technology is represented in Fig. 3.

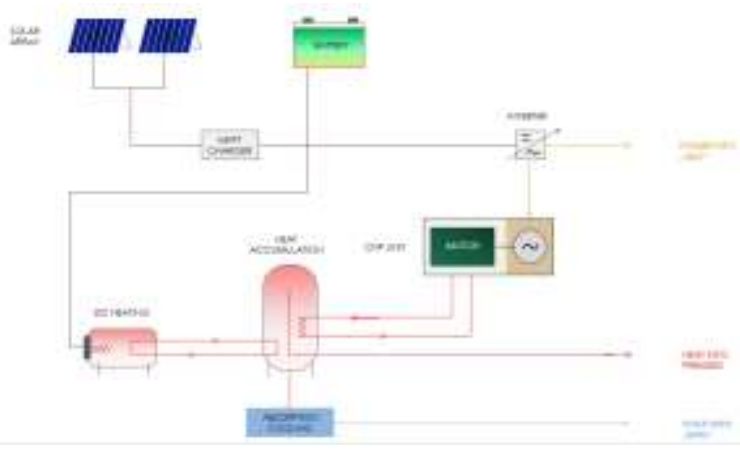

Fig. 3. "SPGS" diagram.

Individual parts of the "SPGS" were designed and implemented as follows:

- The polycrystalline solar panels with a total installed output of $51.48 \mathrm{kWp}$, located on the roof of "A" building, oriented to the East/West.

- 12 units of parallel-connected MPPT solar chargers; voltage system - 2DC $150 \mathrm{~V} / \mathrm{IT}$ input, voltage system -2DC 45-62V/IT output; charging power $1020 \mathrm{~A}$.

- Three triples of sinusoidal hybrid inverters/chargers connected in parallel into the 3-phase system of the 
output power of the system of $58.5 \mathrm{~kW}$; peak output of the system of $144 \mathrm{~kW}$; time of transition to the island mode is 15 milliseconds.

- The TEDOM Micro T30 SPI CHP unit with an electric output of $30 \mathrm{~kW}$ and the heat output of $62 \mathrm{~kW}$. The CHP unit is fitted with synchronous generator with an optional island mode.

- The lithium batteries with a total installed capacity of $80.88 \mathrm{kWh}$; permanent charging current of $960 \mathrm{~A}$, permanent discharging current of $1920 \mathrm{~A}$, and a maximum discharging current of the battery set of $3600 \mathrm{~A}(3 \mathrm{sec})$.

- DC heating of the installed output of $24 \mathrm{~kW}$.

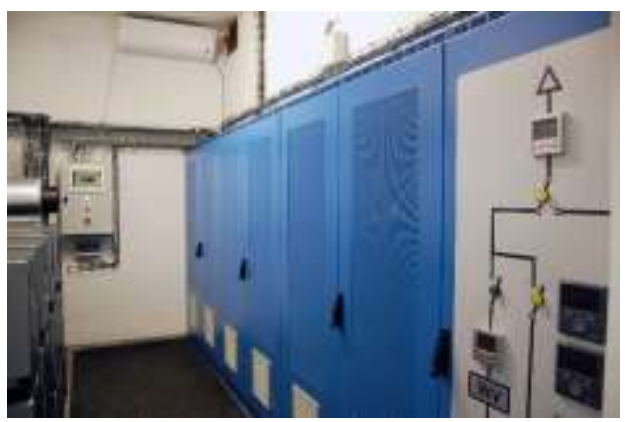

Fig. 4. General view - "SPGS" switchroom.

The actual power plant is composed of the hybrid inverters with an integrated transfer relay on each phase. The inverters allow cooperation with the external source, in this case, the CHP unit.
The power accumulation system is equipped with a battery management which ensures the battery operation in the pre-set SOC (State Of Charge) interval. If the battery is discharged under the pre-set limit, the master control system (M\&R) issues a command for the CHP unit to start. When the top limit of the SOC is exceeded, the master control system stops the CHP unit. The same method is used to control the DC heating process.

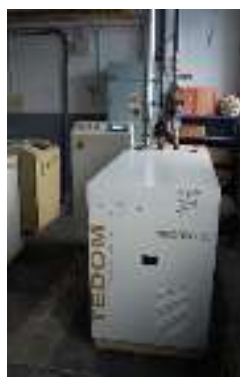

Fig. 5. CHP unit.

The battery set is equipped with a complete BMS (Battery Management System) which provides monitoring of all the main battery parameters - overcharging, undercharging, overcurrent, and temperature and it provides for balancing of the individual battery cells.

The master M\&R system assures monitoring and setting of the operation parameters and it controls the operation of the CHP unit and DC heating process. It also allows for the remote monitoring and data archiving. The $M \& R$ visualization is depicted in Fig. 6.

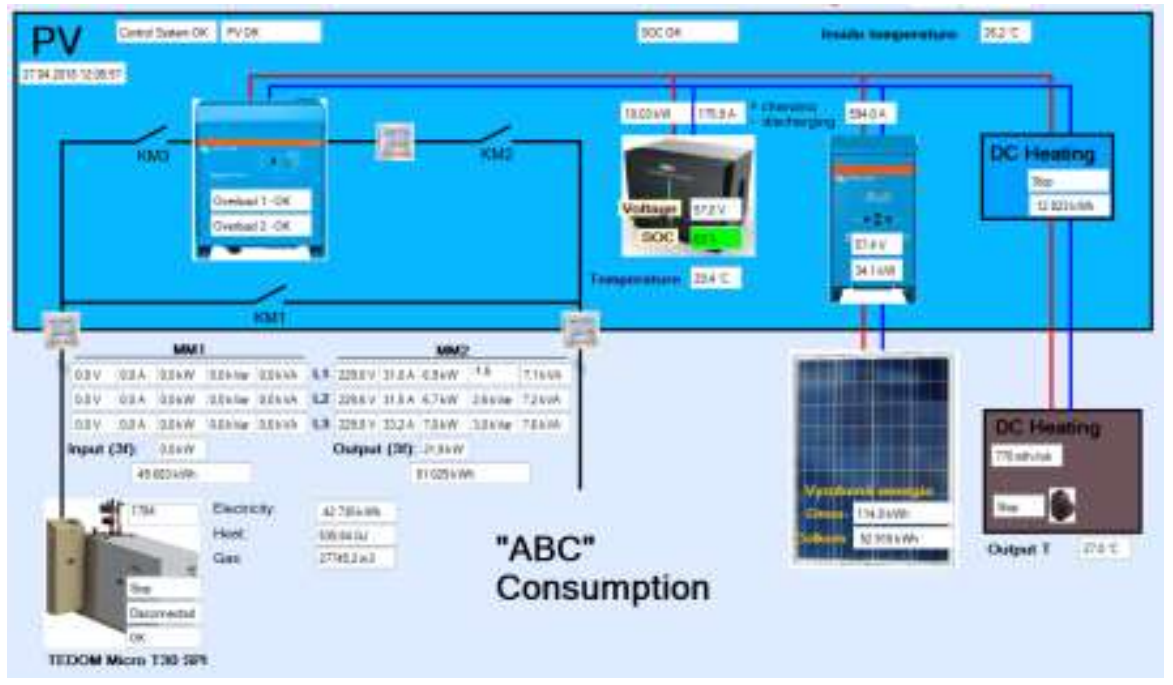

Fig. 6. "SPGS" visualization.

\section{IV. "SPGS" BALANCE}

The consumption of the "A-B-C" buildings is primarily covered from solar energy. If the solar energy is insufficient, it will be supplemented with the CHP unit which consequently copies the building consumption. Solar energy is used to charge the batteries. In case the consumption exceeds the possible current loading of cogeneration, the converters boost the output power of the energy from batteries. If the external source is shut down or fails, the power supply is taken over by the hybrid converters and they are placed into the island operation mode. In case the system is overloaded, the M\&R issues a command to disconnect cogeneration and to phase it back in order to recover the standard status. Processes of the building power input and the outputs of sources are depicted in Fig. 7. 


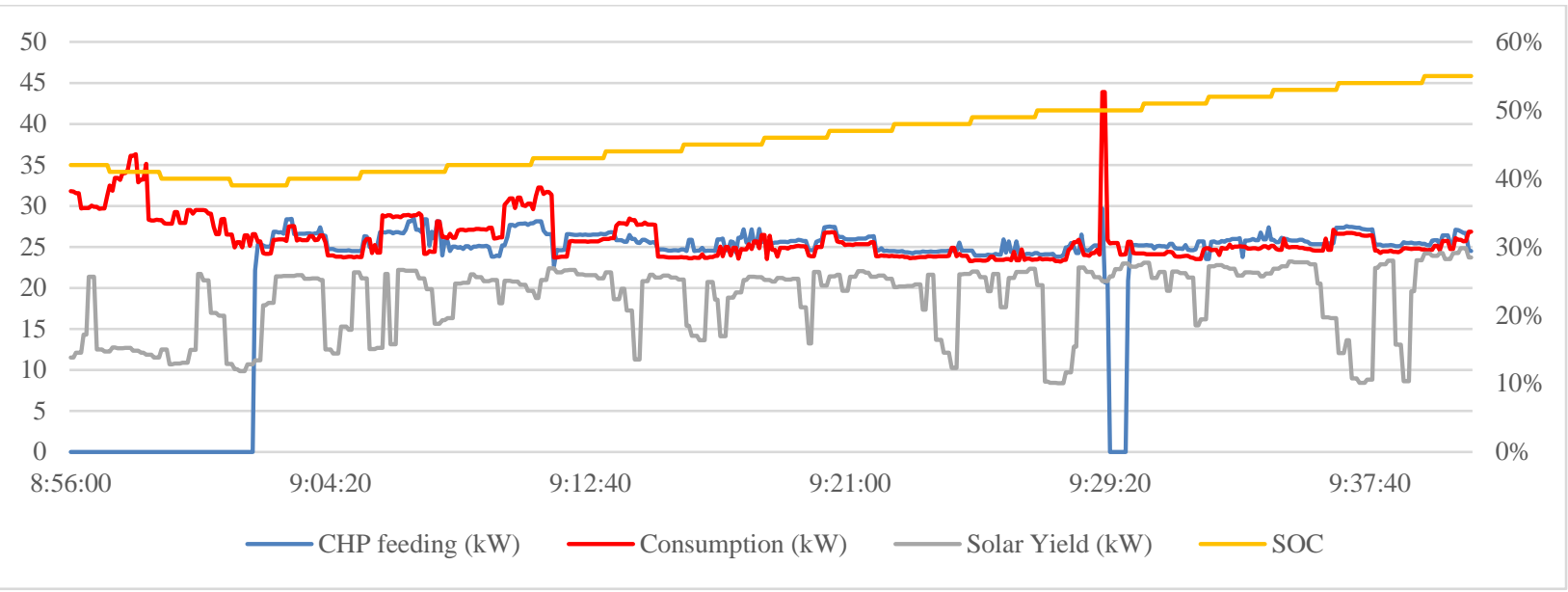

Fig. 7. Power generation and consumption balances.

Blue curve - power input to the photovoltaic power plant (FVE) - illustrates the CHP unit operation. The CHP unit copies the consumption of the buildings (red curve). The status where the red curve is above the blue curve, in other words, where the building consumption is higher than the loading capacity of cogeneration, represents dotation of energy from the batteries. The chart shows increases in current when the materials lift is started and the phases were overloaded and cogeneration is disconnected in a controlled manner.

\section{POWER SOURCE ARRANGEMENT VARIANTS}

Based upon the specific situation of the investor, a large series of combinations of the source outputs and power accumulation amount can be designed. The following comparisons represent a selection from these combinations. For this chart, a series of assumptions that are specified in the text downstream Table I were adopted to facilitate representation of certain dependencies.

TABLE I.

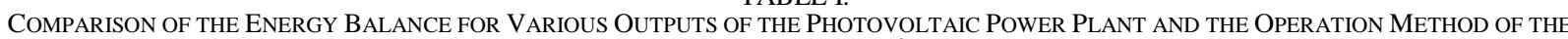
COMBINED SOURCE

\begin{tabular}{|l|l|l|l|l|l|l|l|l|}
\hline & $\begin{array}{l}\text { Unit } \\
\text { per } \\
\text { year }\end{array}$ & $\begin{array}{l}\text { Comparison } \\
\text { scenario }\end{array}$ & $\begin{array}{l}\text { FVE } \\
30 \mathrm{kWp}\end{array}$ & $\begin{array}{l}\text { FVE } \\
50 \mathrm{kWp}\end{array}$ & $\begin{array}{l}\text { FVE } \\
70 \mathrm{kWp}\end{array}$ & $\begin{array}{l}\text { Parallel } \\
\text { operation } \\
\text { CHP unit } \\
\text { +FVE } \\
50 \mathrm{kWp}\end{array}$ & $\begin{array}{l}\text { Off-grid } \\
\text { operation } \\
\text { CHP unit } \\
\text { + FVE } \\
50 \mathrm{kWp}\end{array}$ & $\begin{array}{l}\text { Actual } \\
\text { operation } \\
\text { data }\end{array}$ \\
\hline Power consumption from grid & $\mathrm{kWh}$ & 68000 & 42176 & 24896 & 7712 & 0 & 0 & 0 \\
\hline Purchase of natural gas & $\mathrm{kWh}$ & 340792 & 340792 & 340792 & 340792 & 434605 & 367058 & 381861 \\
\hline Power generation in PV & $\mathrm{kWh}$ & 0 & 26900 & 44900 & 62800 & 44900 & 44900 & 43774 \\
\hline Power generation in cogeneration & $\mathrm{kWh}$ & 0 & 0 & 0 & 0 & 88200 & 38808 & 38813 \\
\hline Supply of power to grid & $\mathrm{kWh}$ & 0 & 0 & 0 & 0 & 26460 & 0 & 0 \\
\hline Heat from cogeneration & $\mathrm{kWh}$ & 0 & 0 & 0 & 0 & 187918 & 82684 & 80405 \\
\hline Heat from DC heating & $\mathrm{kWh}$ & 0 & 0 & 0 & 0 & 0 & 12236 & 10536 \\
\hline Heat from gas boilers & $\mathrm{kWh}$ & 277778 & 277778 & 277778 & 277778 & 89860 & 182858 & 186837 \\
\hline CO2 emissions & $\mathrm{kWh}$ & 130 & 104 & 87 & 69 & 78 & 66 & 69 \\
\hline
\end{tabular}

${ }^{1}$ For simplicity, the nominal electric output of $30 \mathrm{~kW}$ is considered in all cases where a CHP unit is employed. Losses and internal consumptions in the sources and converters are included in the calculation to make it simpler.

The assumed number of CHP unit operation hours in the off-grid operation mode was based on real data.

The natural gas consumption corresponds to the needs to provide the supply of heat that is covered by cogeneration, DC heating or the gas boiler. The surplus power will be used for the generation of heat in the DC heating predominantly on weekends or in the afternoon hours when a very low power consumption and power input amounting to $10 \mathrm{~kW}$ are assumed.

The CO2 emissions are calculated upon the emission factors specified in the Ordinance 480/2012 Coll. on energy audit and energy expertise. Thus, a high emission factor, which corresponds to the power generation from fossil fuels, is used for the purchased electric power. 
From Table I, which compares balances for various outputs of the genuinely photovoltaic sources, it is apparent that when the output of a photovoltaic power plant is further increased, the amount of power utilisable in the premises will increase at a less significant rate. The amount of power which would overflow into the system or which would need to be wasted will simultaneously grow. With the effort to utilise this power to the maximum extent in the premises, the demands for power accumulation will grow rapidly.

The last two columns of the table compare two operation modes of the combined source:

- Parallel operation mode - as standard, the source is connected to the distribution network and the surplus power, if any, from the cogeneration process can be supplied back to the network. The overflows from FVE are eliminated technically. The CHP unit can also be operated with regard to the need for heat.

- Off-grid operation mode - supplying power independent of the distribution network. The power generation balance must cover the consumption in buildings and the surplus heat, if any, from cogeneration must be either wasted or used in the DC heating.

Real operation data confirm the assumed balances stated in Table I. The system efficiency is around $94 \%$ when the CHP unit efficiency is not included.

\section{CONCLUSION}

The aim of the project implemented by TEDOM was to verify the technical possibilities of operation of the combined CHP unit KJ + FVE source in the off-grid mode.

In the company premises, the variant combination was selected upon the balance sheet budget and quantification of the investment costs in the arrangement below:
- the photovoltaic power plant of the installed output of $51.48 \mathrm{kWp}$ with the preparation for extension up to $70 \mathrm{kWp}$,

- the CHP unit of the electric output of $30 \mathrm{~kW}$.

The source is supplemented with the power accumulation of the utilisable capacity of about $50 \mathrm{kWh}$ and the peak output of converters of $144 \mathrm{~kW}$.

Installation of the CHP unit brought optional reduction of the power accumulation size over the projected capacity, it cut down the necessary output of the photovoltaic source, increasing the efficiency of utilisation of the primary energy of the fossil fuels and it contributed to a further reduction of carbon dioxide emissions compared to the purchase of power from conventional sources.

The connection of a renewable source with the prevailing generation of power in the summer season with the CHP unit which has prevailing production in winter season represents an ideal combination. It assures a balanced all-year production of power and it allows for an independent supplying of the premises. At the same time, it increases efficiency in supplying the buildings with energies leading to the year-round utilisation of the produced heat and, consequently, cold. The CHP unit is serviced once a year. The service intervention can be scheduled for the afternoon hours when the power consumption of the premises is lower.

The actual off-grid operation mode is not economically efficient today. Preparation for the extension of a solar panel field will allow completion of the source output when the costs for power accumulation drop down. Then, it will be possible to use the surplus power to charge the corporate electric cars, a project considered for the future.

The operation efficiency grows in case of parallel operation with the distribution network. The indispensable side effect is independency of the distribution network in the case of a blackout. 